crime, and, on his own showing, forgets that there was a long and momentous conversation between Townley and his victim. My letter was written on the 8 th, when my friend Dr. Seymour was alive, and, as far as I knew, in his usual health. His death took place on the 16th inst., and his evidence to corroborate my statement is no longer available. I believe the fact of Townley's conversation, the existence of the document founded upon it, and Dr. Winslow's own statement to Dr. Seymour and myself, have all passed from his mind; and when he recalls or ascertains the facts, he will feel regret for his hasty denial of the truth, and still more lament the intemperate and offensive language he has allowed himself to use.

As far as I am concerned, I here terminate this unhappy dispute. I will only say, in conclusion, that my evidence before the Commission does not warrant Dr. Winslow's assertion at the end of his letter: that it is "the most cruel and unjustifiable attack ever made upon the honour, honesty, and integrity" of our profession. From Dr. Winslow's veràict I appeal to that of my professional brethren, and especially to those among them engaged in the same studies as myself, many of whom are among my dearest friends.

$$
I \text { am, Sir, yours \&c. }
$$

Albemarle-street, April 2th, $1860 . \quad$ HarRINGToN TUKe.

\section{MR. H. LEE ON SYPHILIZATION.}

To the Editor of THE LANCET.

SIR, -In the lectures on "Syphilitic Inoculation in 1865" by Mr. Henry Lee, lately published in THE LANCET, there are certain statements relating to the patients treated by Professor Boeck, under my observation, in the Lock Hospital, which require a great deal of qualitication; and with reference to which, on behalf of the Professor, who is not here to speak for himself, I trust you will permit me to say a few words.

In The LaNcer of April 7th, Mr. Lee says, speaking of the immunity alleged to be obtained by repeated inoculation with syphilitic matter : "It is a fact worthy the serious consideration of the profession, that the immunity itself is a thing not so easily produced. During the four months that Prof. Boeck remained in this country, he has produced, as was supposed, immunity in two patients only. Mr. James Lane was good enough, after the immunity was supposed to be established, to allow me to perform a fresh inoculation upon each patient. A specific pustule was in each case produced; and from one of these Mr. Lane himself again inoculated." This statement is repeated in THE LANCET of April 14th.

The natural inference is that Dr. Boeck was mistaken, and that no real immunity was obtained after all. Most readers would probably also infer that the inoculations in these patients occupied a period of four months. The following are the real facts, a correct appreciation of which is important at the present time, when syphilization is, to a certain extent, sub judice by the profession in this country :-Dr. Boeck's first inoculation was made on these patients on Sept. 5th ; his last successful inoculation was made in each of them on Dec. 16th: a period, not of four months, but of three months and eleven days. I mention this because, in estimating the practical value of syphilization, the element of time is important. After the 16 th of December they were several times inoculated by Dr. Boeck, and the result being negative, he pronounced that immunity had been obtained; and seeing that the secondary affections for which the treatment had been undertaken had disappeared, he considered them as cured. To test the immunity, Mr. Lee requested to be allowed to make a final inoculation with matter of his own selection. The request was at once granted, and he accordingly inoculated them on the 23rd of December. Three days later a small pustule was found in each of them at the site of Mr. Lee's puncture; and these were considered by Mr. Lee to be specific.

To test the character of these pustules, I inoculated from them carefully on the 27th December, making two punctures in each case. In Case 1 no effect was produced. I repeated the experiment on the 30th December, with the same negative result. Now the only test of a successful syphilitic inoculation is that the pustule shall secrete matter capable of reinoculation since any irritant inserted under the skin may produce a pustule more or less perfect. Here, the result of this test, twice carefully applied, was negative; and therefore there is no evidence to show that Mr. Lee's pustule was, as he alleges, specific. I may add that Dr. Boeck objected to the mode of inoculation practised by Mr. Lee, thinking it likely to produce a pustule under any circumstances, and therefore calculated to mislead. After Dr. Boeck left England, I inoculated this patient with matter from a suppurating bubo, and obtained a small pustule, like Mr. Lee's ; but from this, in like manner, I was unable to reinoculate. Three subsequent attempts to inoculate this patient failed altogether. Therefore, so far from disproving the immunity, the result of Mr. Lee's inoculation, and of those made by me subsequently, conclusively show that an immunity as complete as can ever be expected was obtained. in this case.

In Case 2 the immunity was one degree less perfect, since my inoculations from Mr. Lee's puncture produced two pustules ; they were, however, very imperfect ones, and from them I failed to again inoculate. I afterwards inoculated this patient three times with other matter, and obtained small pustules, but could not inoculate a second time from any of them. On a fourth attempt I failed altogether. Short of absolute immunity, then, this was the nearest possible approach to it. In both cases Mr. Lee's pustule healed in about ten days.

These facts were not unknown to $\mathrm{Mr}$. Lee, for I communicated them to him at the time; it is with some surprise, therefore, that I find he has passed them over altogether without notice.

It is right to mention that an approximate, rather than an absolute, immunity was all that was aimed at by Dr. Boeck, or considered necessary by him as a matter of treatment; and this appears to be obtainable, on an average, in about three months. In five cases, however, the treatment of which was commenced by Dr. Boeck and concluded by myself, a complete immunity, equivalent to that in Case 1 , was obtained after inoculation for periods of six and a half, nine, ten, eleven, and twelve weeks respectively.

In The LANCET of April 14th there is another statement on which I find it necessary to remark. Mr. Lee, speaking of the difficulty of inoculating the matter of an indurated sore successfully on a syphilitic patient, says, "Dr. Boeck during his residence in England did not, I believe, succeed in producing such a result in any one instance." Mr. Lee's belief is erroneous. Dr. Boeck succeeded undoubtedly in one case in pro ducing "a lineal series of inoculations from an uncomplicated indurated sore." The patient from whom the matter was taken was under the care of $\mathrm{Mr}$. Walter Coulson, and was one of the two mentioned by Mr. Lee, whom Mr. Coulson afterwards "auto-inoculated" successfully. From this man Dr. Boeck inoculated one of the female patients. The pustules obtained were well developed. They went through a lengthened series, and were transferred to several of the other patients. That Dr. Boeck did not succeed more frequently arose from the fact that the opportunities for obtaining good indurated sores to inoculate from are few. The scanty secretion which such sores afford is not well adapted for conveyance from place to place ; well-marked examples of them are rarely met with except in males, and it was, I believe, only on two or at most three occasions that the attendance of a male patient at the female Lock Hospital was procurable for the purpose. I may add that since Dr. Boeck left, Mr. Gascoyen and I have, each of us, succeeded unequivocally in obtaining a lengthened series of pustules with matter from indurated sores.

Mr. Lee says he was informed by Dr. Boeck that he treated nineteen patients affected with constitutional syphilis in the female Lock Hospital by repeated inoculation. Mr. Lee adds: "Some four or five other cases may have been subjected to the same treatment, which, not having been continued from various causes, are not included in the above-mentioned number." The treatment was discontinued, not in four or five or any other conjectural number of cases, but in one only. The patient was a married woman, who was compelled to leave the hospital, contrary to her own wish, in consequence of the serious illness of her husband. Surely if it was worth while to allude to such a circumstance at all, it was worth while to have ascertained the facts a little more accurately than this.

Again, Mr. Lee says, "these women submitted to the treat. ment under the idea that in future they would not be liable either to receive or communicate disease." This is not the case. The treatment was proposed to them solely as a curative measure, which would save them from a mercurial course, and which it was expected would prevent their having further relapses. It was expressly enjoined by me that no such idea as that mentioned by Mr. Lee should be conveyed to any of the patients.

Mr. Lee further says, that " of those who have been thus treated"-viz., by syphilization, "one death was recently 
mentioned at the Medical Society to have occurred; and another case in which the treatment was attempted has lately died in the Lock Hospital." This is undoubtedly correct. But I submit that if it had been desired to state the facts fairly to the profession rather than to disparage syphilization, it would not have been superfuous to add that in the case mentioned at the Medical Society by Mr. Dumn, it was fully explained by that gentleman that the death was in no degree attributable to or accelerated by the syphilization; and that the patient who died a fortnight ago in the Lock Hospital, diecl of an enormous enlargement of the liver from waxy degenera tion, for which she had been for some time under treatment by Dr. Sieveking. In this case, so far from the result being in in any way assignable to syphilization, it is a very remarkable circumstance that out of forty-three occasions on which this patient was inoculated, with matter from every variety of source, on two only was anything approaching to a positive result obtained, and the pustules were then very small and of brief duration.

Speaking of syphilization, and of the interest excited by Dr. Boeck's visit to England, Mr. Lee says, "it is due to the profession and to the public that the evidence afforded upon the subject should be fairly given." And again, that "we are bound, as students of facts, to state fairly the results obtained under the circumstances." In these sentiments I cordially concur. Whether they have been acted up to by Mr. Lee I will, after what I have said, leave the readers of The LanceT to judge.

I disclaim, on the part of all concerned, the slightest intention to suppress or withhold evidence on this subject. It has been my purpose all along, I have publicly expressed it more than once, to lay before the profession in due time a full account of all the cases treated in the Lock Hospital by syphilization. I hope, in conjunction with my colleague, Mr. Gascoyen, to have the privilege of doing this through the medium of the Medico-Chirurgical Society, where the subject can be fully and fairly discussed. I should have been delighted at any time to furnish Mr. Lee, had he applied to me, with full and authentic particulars; but I think I have some reason to complain when $I$ find that cases which have been under my responsible charge throughout, which possess con siderable public interest and importance, and an account of which I am at this present time preparing for publication, have, without any previous communication with me, been commented upon and prejudged in this off hand and hearsay fashion.

I am anxious to have it understood that $I$ am not writing as a champion of syphilization, on the merits of which I wish to reserve my opinion and to maintain for the present an entirely neutral position. I am very desirous, however, that it should have fair play, and also that no injustice should be done to Dr. Boeck, for whom I entertain a very sincere respect.

I am, Sir, your obedient servant, JAMES R. LANE, F.R.C.S.

Berkeley-street, Piccadilly, April 16th, 1866.

\section{THE EXPANDING UTERINE STEM. To the Editor of THE LANCET.}

SIR,-As the object of my communication in your valuable journal of March 17th, relative to Dr. Henry G. Wright's " new instrument," first described on the 24 th of last February, was solely to put forward my claims as inventor of a stem in March, 1864, introduced by means of a stilette, upon the withdrawal of which it expanded laterally in the body of the nterus, I purposely avoided any discussion upon the utse and abuse of such an instrument; therefore Dr. Wright is perfectly correct in his inference "that I had good reason for the omission" of all reference to flexions of the nterus. But as Dr. Wright appears to think I ought to have alluded to the mechanical treatment of such flexions, which I was anxious to avoid, as I differ from him most materially, I now very reluctantly feel called upon to make brief allusion to those conditions.

I have frequently, from the 8th of May, 1864, to the 1st of August, 1865, used my bilateral expanding stem in flexions of the uterus, in which slight congestion, due simply to flexure so ably depicted by Boivin, Planche IX., Fig. 6, and where division of the cervix uteri had not been previously effected, solely with the view of curing malpositions. In many of the cases the results were so unsatisfactory that since August I have only ventured in two cases to use the expanding stem for that purpose, I cannot any longer refrain from cantioning your readers against the evils resulting from this practice. In one of these cases death ensued from metro-peritonitis last Angust, whilst I was in Edinburgh. The young lady was cautioned to have it removed if it occasioned the least discomfort; but she was so anxious to be cured of her malposition tlat she retained it for ten days in spite of great pain, for which, when it became intolerable, she sent to Dr. Eastlake. That gentle. man at once removed the stem, and ordered appropriate treat. ment. She subsequently placed herself in the hands of a homoopath, under whose care she died.

I am now using the ordinary silver stem in cases of anteflexion of the uterus. I am quite of Dr. Wright's opinion, "that the hysterotome is now-a-days employed very indis. criminately." Still in three of the cases above alluded to, where my expanding stem with a very moderate spring could not be borne, division of the cervix was successful; two of the patients, after being sterile for years, have since become pregnant, and been safely confined of living children. I may further remark that I do not think anyone is justified in introducing a stem into the body of a retroflected uterus, now we possess such safe contrivances as Hodge's pessaries, which, if skilfnlly used, and in appropriate cases, rarely or never fail ; and I can endonse the words of that truthful and trustworthyauthority, Dr.Churchill: "I have now used it (Hodoe's pessary) in many cases without a single failure." Might I ask Dr. Wright to refer me and your readers to the writings of any authority prior to March, 1864, in confirmation of his statement that in the construction of intra-uterine stems, pessaries, or tents, "there is really nothing new in the nse of a spring"? also where in Kiwisch"s writings it is stated that he "first employed it for dilatation of the cervix"? I shall likewise feel indebted to Dr. Aveling if he would give me more definite information concerning the spring tent found "in a drawer in the small room adjoining Sir J. Y. Simpson's ward." In Dr. Aveling's words, "I can learn nothing about it, except that it had been there a long time." Where can I find any record of that tent, and what is the date of its invention? What is that gentleman's definition of "a long time"? Can Dr. Aveling affirm that it is not mine? These, I submit, are fair questions when the originality of an invention is in dispute. Why did Dr. Wright copy Dr. Marion Sims's modification of my stem, when he could have seen a fac-simile of my original stem in the instrument. case at the Samaritan Hospital (of which he is one of the medical officers), at Coxeter's, at Weiss's, or at my kouse?

Dr. Wright states: "I carefully searched through all the records" (vide Dr. Routh's pamphlet), "but found nothing to help me. I personally investigated the most recent instruments in the stores of three eminent makers-Maw, Coxeter, and Savigny. Failing to find what I required, I devised the instrument described in my paper," \&c. After reading this statement, I went to Coxeter's and bought one of my stems, and was informed that a similar one was sold to Dr. Routh on the 3rd of December, 1864, and described and exhibited by him in the same year. The foreman of that establishment also told me that they have always called the instrument and sold it as "Greenhalgh's spring tent," and that they always keep a stock of various sizes, numbered like catheters.

I never affirmed, in writing or otherwise, that my expanding stem could "only be used after the incision of the cervix, or dilatation of it by a sponge or sea-tangle tent." These are the words of Dr. Marion Sims, quoted by Dr. Wright, which $T$ have not and do not endorse. Moreover I have never used a sponge or sea-tangle tent prior to its introduction. Almost every difficulty can be met by size and curve; still I have occasionally had recourse to a dilator.

If Dr. Wright would "very carefully" word his reply, as he has kindly given me the credit of doing, and not impute impressions as to his motives to me and others, but simply adbere to facts, much good might be done by fair and open discussion.

From the pressure of public and private professional engagements, I am sorry $I$ have been prevented from replying earlier to Dr. Wright's letter of the 24th of March.

I am, Sir, your obedient servant,

Grosvenor-street, April 1\&th, 1E66. R. GREENHALCH, M.D.

\section{ON THE FUNCTIONS OF THE CEREBELLUN. To the Editor of THe LaNcert.}

SIR,--In your review of Professor Owen's "Comparative Anatomy and Physiology" I find it stated that his views are adverse to the existence of any relation between the cerebellum and the sexual instinet as mojntained by Dr. Gall, but in 